\title{
PLANAR MAGNETICS FOR OPTIMISED MANUFACTURING, PERFORMANCE AND LIMITATIONS
}

\author{
Erich Strixner $^{(1)}$, Dr. Frank Herty ${ }^{(2)}$, Vittorio Pascucci $^{(3)}$ \\ (1) Airbus Defence and Space (Airbus DS GmbH), Robert-Koch-Str. 1, 82024 Taufkirchen, Germany, Email: \\ Erich.Strixner@airbus.com \\ (2) Airbus Defence and Space (Airbus DS GmbH), Claude-Dornier-Str.88090 Immenstaad, Germany, Email: \\ Frank.Herty@airbus.com \\ (3) Former Airbus Defence and Space (Airbus DS GmbH), Robert-Koch-Str. 1, 82024 Taufkirchen, Germany, Email: \\ VittoPascu@gmail.com
}

\begin{abstract}
The LION Navigator, as a standard product line of Airbus Defence and Space, has started a design for manufacturing initiative for switched mode power supplies in the year 2010 .

An analysis of the overall production effort of power supplies reveals that a high proportion is related to hand soldering of through-hole parts, integration of the PCB into the frame and conventional magnetics which are manufactured with low automatization. A concept study was originated to evaluate the technical prospects for an improved design for manufacturing strategy.

The technical approach is related to substitution of remaining through-hole parts by SMD devices if it is economic, to cool Power-SMDs via PCB to structure and, last but not least, to replace conventional magnetics with planar ones, as main part of the study. The windings of planar magnetics are integrated into the PCB with a highly automated process. They provide advantages due to good cooling capability and a low component height but advanced calculation methods are necessary to succeed in the design. As a follow up to the study the development of the power converter for the LION Navigator was started in order to detail the hardware related to an improved design for manufacturing.
\end{abstract}

\section{INTRODUCTION}

The surface mount technology was developed by IBM in the 1960s and became widely used in the late 1980s. Hardware gets much smaller due to reduced part sizes and by a placement on both sides of the PCB. Planar Magnetics integrated into a PCB came up in the 1990s to achieve a flat design of magnetics combined with optimised manufacturing capability. Power applications were limited that time because PCB technology was not advanced as it is today. Multilayer PCB Technology is a standard now with sufficient copper density for space applications as well. This offers the opportunity to integrate magnetics into the $\mathrm{PCB}$. The manufacturing line gains in a reduced manufacturing effort compared to conventional magnetics where enamelled copper wires are wounded on U-, E-, Pot - or Toroid Cores. Planar magnetics have a low height but need more PCB area compared to wire wound standard magnetics. The proximity losses are lower due to the different winding geometry achieving advantages for high current applications. E-Planar cores allow the development of traditional transformers and chokes as well as integrated planar magnetics to achieve optimized core utilization. The development is more oriented towards a prediction of performance with a mathematical approach in order to limit the development time.

\section{PRODUCTION EFFORT FOR POWER CON- VERTERS}

\subsection{Through-Hole Parts}

In the last decades the manufacturing technology for space hardware has changed. The traditional approach of using parts in through-hole technology [THT] is depicted in Figure 1. There are a lot of different manufacturing steps necessary to finalise a power converter for space applications. Manual work by population of THT parts, preparing wires, hand soldering, screwing of power semiconductors to the frame especially is time consuming and limits the production output of hardware.

\subsection{Magnetics}

The most common approach for magnetics is the usage of coated toroid ring cores as depicted in Figure 1 where enamelled copper wire is directly applied. E- Cores, RM-Cores and pot cores with coil former, needs less manufacturing effort because of simple and well known automatization techniques. Additionally, a set of tests are necessary to prove their workmanship and their quality level. This is needed because they consist of a combination of a core or core half's, enamelled copper wire, in some cases a coil former and of the coating to resist against humidity and particles. In conclusion, magnetics are complex and time consuming parts that have a high contribution to the overall parts cost. 


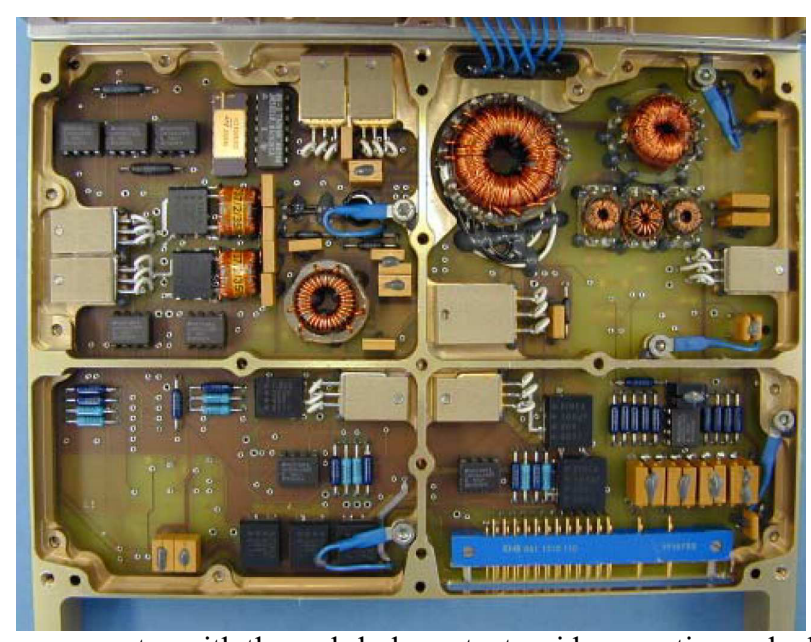

Figure 1: Traditional power converter with through-hole parts, toroid magnetics and a lot of manual mountings.

\subsection{Integration of the PCB into the frame}

The integration of a populated PCB containing power converter hardware consists of a number of manual tasks.

Screwing of TO packages to the frame and connecting the pins to the PCB via flex or wire and, in some cases crimped connectors are used where every pin has to be connected to a single wire. These steps are necessary for this kind of technology to achieve a reliable operation under high vibration loads as a standard for space hardware.

\section{OPTIMISED MANUFACTURING}

The concept study done at Airbus DS in 2010 was initiated to develop solutions for manufacturing of improved power converters. The manual or less automated production steps as described in the chapter 2 shall be optimised as much as possible reaching performance data similar to conventional power converters.

\subsection{SMD power devices}

It is nowadays a standard to use nearly $100 \%$ SMD parts for all small signal components. There are a few exceptions where no SMD parts are available on the space market or if THT parts are high runners with economic preference.

Most SMD power parts are small in size and they guarantee an efficient automated mounting. The drawback is that it is difficult to cool them when they are mounted on the PCB. A SMD 0.5 device for example has a limited dissipation of about $500 \mathrm{~mW}$. Higher power capabilities without losing standard mounting are possible by cooling of SMDs directly through PCB or substrate to structure.

\subsection{Integration of magnetics into the PCB}

The windings of planar magnetics are integrated into the PCB with a highly automated process shown in Figure
2.

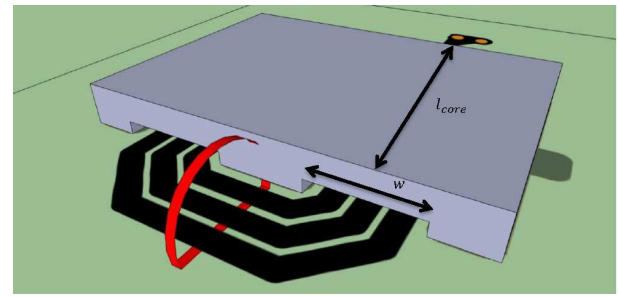

Figure 2: Planar magnetic with windings integrated into the PCB.

There are 4 different kinds of mechanical constructions suited for planar magnetics.

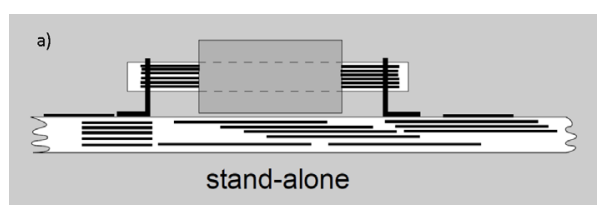

Figure 3: Stand-alone mounting as in [1].

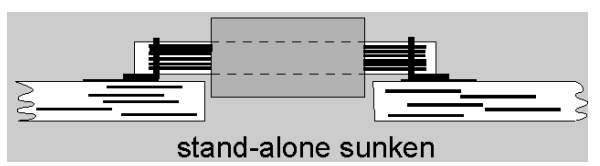

Figure 4: Stand-alone sunken mounting as in [1].

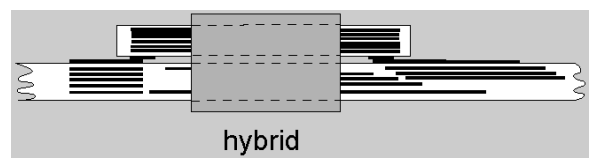

Figure 5: Hybrid mounting as in [1].

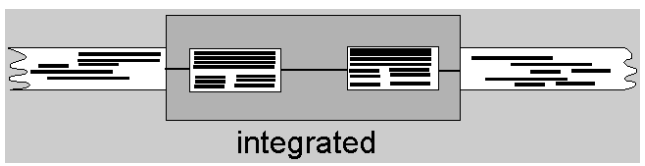

Figure 6: Integration in an existing PCB which is additionally used for the population of parts as in [1]. 
The hybrid and integrated mounting techniques are mechanically stable and provide a high copper utilization as well. They are best suited for the high environmental requirements related to space applications.

\section{ENVIRONMENTAL CONDITIONS FOR QUAL- IFICATION}

\subsection{Vibration Loads}

\subsubsection{Sine Vibration}

Airbus DS GmbH has already finalised an ESA Qualification for planar magnetics. Only mature mechanical constructions withstand the high vibration levels related to space requirements. The used vibration levels are shown in Table 1.

Table 1: Sine Vibration Qualification Levels

\begin{tabular}{|c|c|c|}
\hline Frequency $[\mathrm{Hz}]$ & Load & Sweep Rate \\
\hline $5-20$ & max. shaker ampl. & 2 oct $/ \mathrm{min}$ \\
\hline $20-100$ & $20 \mathrm{~g}$ & $2 \mathrm{oct} / \mathrm{min}$ \\
\hline $100-200$ & $15 \mathrm{~g}$ & $1 \mathrm{oct} / \mathrm{min}$ \\
\hline
\end{tabular}

\subsubsection{Random Vibration}

The random vibration levels are shown in Table 2.

Table 2: Random Vibration Qualification Levels

\begin{tabular}{|l|c|c|}
\hline Axis & Frequency $[\mathrm{Hz}]$ & $\begin{array}{c}\text { Qualification Lev- } \\
\text { el }\end{array}$ \\
\hline \multirow{2}{*}{$\begin{array}{l}\text { Parallel to mount- } \\
\text { ing plane }\end{array}$} & $20-80$ & $+3 \mathrm{~dB} /$ oct. \\
\cline { 2 - 3 } axis) & $80-400$ & $0.1 \mathrm{~g}^{2} / \mathrm{Hz}$ \\
\cline { 2 - 3 } & $400-2000$ & $-3 \mathrm{~dB} /$ oct. \\
\cline { 2 - 3 } & $\mathrm{G} \mathrm{rms}$ & 10.0 \\
\hline $\begin{array}{l}\text { Perpendicular to } \\
\text { mounting plane }(\mathrm{Z} \\
\text { axis) }\end{array}$ & $20-80$ & $+3 \mathrm{~dB} /$ oct. \\
\cline { 2 - 3 } & $80-400$ & $0.5 \mathrm{~g} / \mathrm{Hz}$ \\
\cline { 2 - 3 } & $400-200$ & $-6 \mathrm{~dB} / \mathrm{oct}$. \\
\cline { 2 - 3 }
\end{tabular}

\subsubsection{Shock}

The shock levels are shown in Table 3

Table 3: Shock Qualification Levels

\begin{tabular}{|l|c|c|c|}
\hline Frequency & $100 \mathrm{~Hz}$ & $2 \mathrm{kHz}$ & $10 \mathrm{kHz}$ \\
\hline $\begin{array}{l}\text { Shock response spectrum } \\
(\mathrm{Q}=10) \text { at unit interface }\end{array}$ & $20 \mathrm{~g}$ & $2000 \mathrm{~g}$ & $2000 \mathrm{~g}$ \\
\hline
\end{tabular}

\subsection{Thermal Vaccum Test}

The thermal vacuum test data are:

$\begin{array}{ll}\text { Duration: } & 7 \text { days } \\ \text { Temperature: } & 80^{\circ} \mathrm{C} \text { under } \\ \text { Pressure: } & 1 \times 10-5 \mathrm{~Pa}\end{array}$

\subsection{Thermal cycling}

Number of thermal cycles: 200

$\begin{array}{ll}\text { Temperature ranges: } & -55^{\circ} \mathrm{C}\left(-5^{\circ} \mathrm{C} /+0^{\circ} \mathrm{C}\right) \text { to } \\ & +110^{\circ} \mathrm{C}\left(+5^{\circ} \mathrm{C} /-0^{\circ} \mathrm{C}\right) \\ \text { Ramp rate: } & 10 \pm 2^{\circ} \mathrm{C}\end{array}$

Dwell time at temperature extreme: 15 minutes
The duration of each cycle amounts to 1 hour.

\section{MECHANICAL CONSTRUCTION OF PLANAR MAGNETICS}

\subsection{Requirements on the PCB}

The usage of a PCB layer stack with high copper utilization is preferred. This allows an adequate power density resulting in a competitive size of planar magnetics. A copper thickness of $70 \mu \mathrm{m}, 105 \mu \mathrm{m}, 210 \mu \mathrm{m}$ up to $400 \mu \mathrm{m}$ ensures a high power density especially in high current applications. A copper thickness up to $210 \mu \mathrm{m}$ supports high frequency operation with planar magnetics without exceeding acceptable proximity losses in most of the applications.

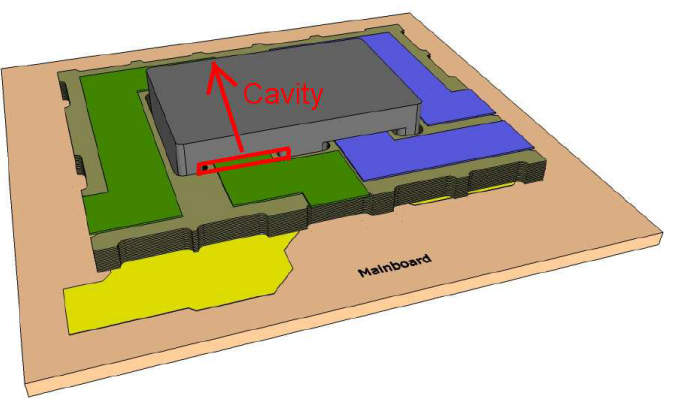

Figure 7: Integrated planar magnetic as in [3]

\subsection{Requirements on the planar mounting}

Planar magnetics are used for commercial electronics since more than 2 decades. This mounting approach is considered as far as possible, due to its strong heritage. This ensures a low risk for the qualification campaign.

\subsection{Requirements on the coating}

There are different coatings commonly used for space applications. Some of them are Mapsil, Nusil and Parylene C. The first two are silicone conformal coatings while the last one is a polymer film type. Populated PCBs for space have to withstand hard environmental conditions such as vibrations and thermal cycling as described in chapter 4 . The combination of PCB, part construction, mounting technique and coating forms a system that has to perform well under these conditions. EI- or EE-planar magnetics as shown in Figure 2 and Figure 7 are glued to the Motherboard on the bottom side. On the topside of the PCB there are two cavities left for mechanical margin as, in the construction of planar magnetics (e.g.: EE, EI, RM cores), the thermal expansion coefficient of coatings commonly used in space is different to that of ferrite materials. 
Table 4: Property assessment of well-known conformal coatings

\begin{tabular}{|l|l|}
\hline $\begin{array}{c}\text { Silicone conformal coatings: } \\
\text { Mapsil, Nusil }\end{array}$ & \multicolumn{1}{|c|}{$\begin{array}{c}\text { Polymer film conformal } \\
\text { coating: Parylene C }\end{array}$} \\
\hline $\begin{array}{l}\text { Silicone is roughly equivalent } \\
\text { to a very soft rubber. }\end{array}$ & $\begin{array}{l}\text { Nonporous and transparent } \\
\text { polymer film }\end{array}$ \\
\hline $\begin{array}{l}\text { The liquid can be applied via } \\
\text { spraying, dipping or brushing. }\end{array}$ & $\begin{array}{l}\text { Applied by vapour based dep- } \\
\text { osition. It offers the best pos- } \\
\text { sible coverage of any confor- } \\
\text { mal coating material }\end{array}$ \\
\hline $\begin{array}{l}\text { Thick coat is needed to be } \\
\text { effective. Per IPC Standards, } \\
\text { between 76um and 203um }\end{array}$ & $\begin{array}{l}\text { Forms a thin coating between } \\
10 u m \text { and 15um (50um max). }\end{array}$ \\
\hline $\begin{array}{l}\text { The reproducibility depends } \\
\text { on the process automatization. }\end{array}$ & $\begin{array}{l}\text { High reproducibility in thick- } \\
\text { ness due to deposited as a } \\
\text { vapour in a vacuum chamber. }\end{array}$ \\
\hline It tends to fill cavities of parts & $\begin{array}{l}\text { It does not fill cavities of parts } \\
\text { due its thin thickness and the } \\
\text { applied deposition technique. }\end{array}$ \\
\hline
\end{tabular}

A way to avoid mechanical stress around the cavities as shown in Figure 7 is to use a thin coating like Parylene-C which guarantees good coverage on nearly inaccessible areas as well. As a result the cavities are not filled with coating avoiding pressure to the ferrite core. Such a mismatch in expansion coefficient in combination with filled cavities can lead to fail in qualification by cracks in the ferrite material or by a lift-off of the core half on component side.

\section{OVERVIEW OF APPLICATIONS}

The first application which was optimised for manufacturing is the power supply for the LION Navigator followed by a mass memory hardware related to high output current up to $30 \mathrm{~A}$. The range was finally completed by a high voltage application in the $\mathrm{kV}$ range.

\subsection{Lion Navigator}

The power converter for the LION Navigator as part of the standard product line of Airbus DS GmbH is depicted in Figure 8. It converts the primary power bus into 3 insulated output voltages with an output power of $30 \mathrm{~W}$. Customer specific requirements demand an operation on the unregulated $28 \mathrm{~V}$ and the regulated $50 \mathrm{~V}$ bus with minor adaptations of small signal parts only. Therefor the converter has a wide input voltage range from $16.5 \mathrm{~V}$ to $55 \mathrm{~V}$. The PCB features 9 planar magnetics with different functions. The input filter, the power and the current transformer, the secondary common mode filters, a small signal pulse transformer and a $1 \mathrm{MHz}$ oscillator. In this first application only one magnetic was implemented in a conventional way. This was an initial learning curve which led to an improvement of calculation methods of magnetics. The modelling of leakage inductance and, more important, capacitive coupling within the winding arrangement helps to reduce iteration loops in the design and to treat issues before the first hardware is built. An estimation of the leakage inductance is needed to calculate the losses in snubbers and clamping networks. Knowledge of capacitive coupling is valuable to determine common-mode and differential-mode coupling in filters and transformers.

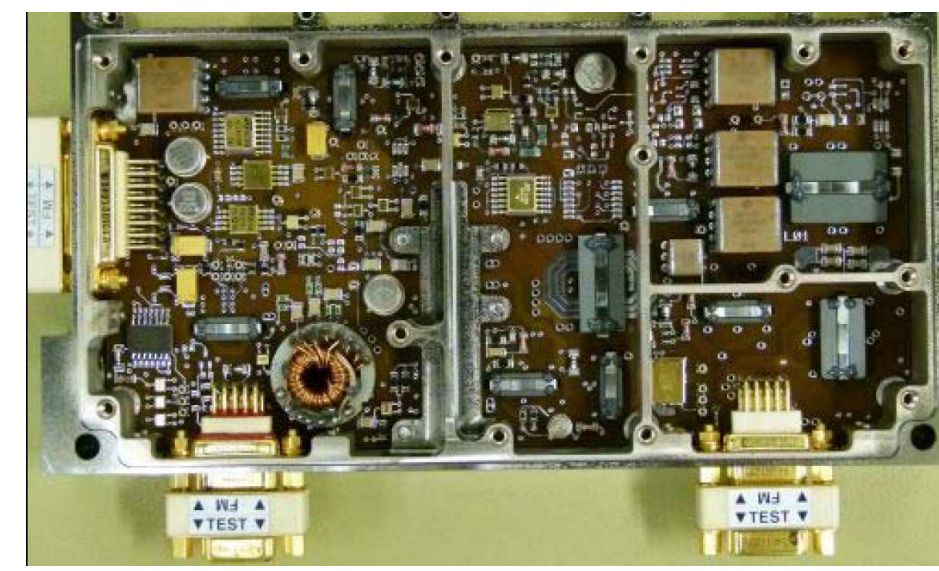

Figure 8: Power supply for the LION Navigator with FM status, Outputs $=3.3 \mathrm{~V}, 5.0 \mathrm{~V}, 9.2 \mathrm{~V}$; Sum $30 \mathrm{~W}$; Input: $16.5 \mathrm{~V}$ to $55 \mathrm{~V}$

\subsection{Mass Memory}

The PSO Mass Memory Converter depicted in Figure 9 operates on a $28 \mathrm{~V}$ power bus and supplies $3.3 \mathrm{~V} / 30 \mathrm{~A}$ to the digital load. It is optimised for the production line by the use of planar magnetics, cooling of SMDs via $\mathrm{PCB}$ to structure. The mounting of the populated PCB into the frame is simple because all parts are directly mounted on the PCB. All windings are integrated into a 10 layer PCB. No temperature cycling of the magnetics is necessary to prove workmanship of the winding arrangement. Parylene-C coating guarantees to apply no stress to the magnetic cores and is applied in one step 
for all the other populated parts. A verification of the inductance is performed as an in-circuit measurement on the populated board.

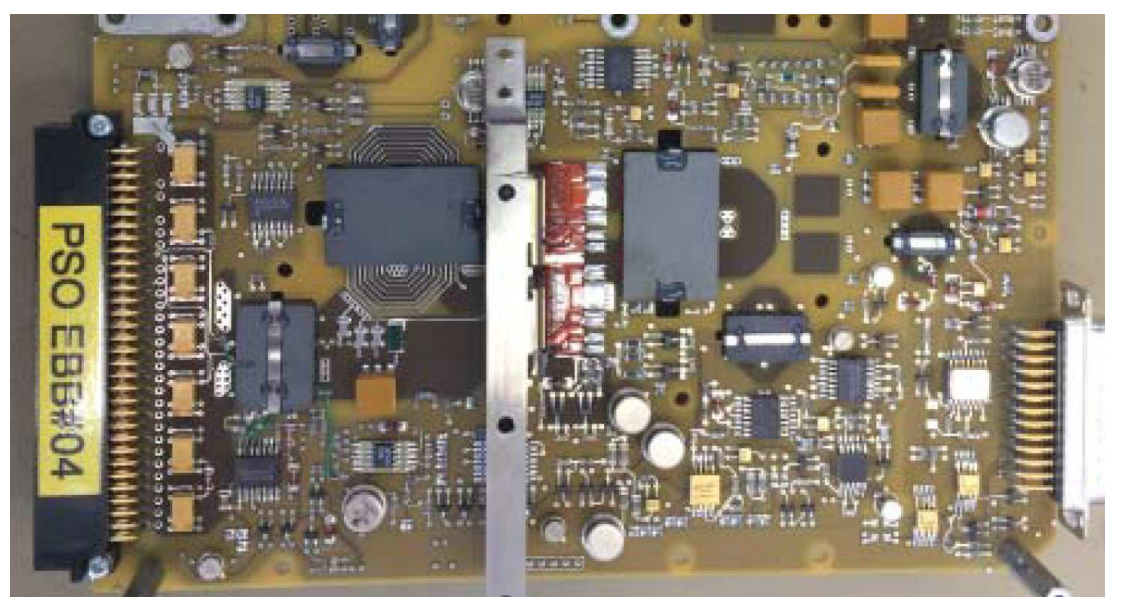

Figure 9: NGSAR-CE, 3.3V/30A

\subsection{HVHP technology development}

Airbus DS GmbH completed research activities in order to extend the field of applications to high voltage planar magnetics. Thanks to the DLR technology development program called "HVHP" (FKZ:: $50 \mathrm{RN}$ 1302) a $2 \mathrm{kV}$ high voltage planar transformer prototype was developed and tested successfully. The prototype is shown in
Figure 10. While this kind of transformer has almost the same performances in terms of mass and dissipation, the expected cost savings for manufacturing can be reduced to roughly $50 \%$ compared to the toroidal version of the transformer. The reasons for this are the simpler geometry and hence, the simpler potting process and reduced effort in terms of in-production testing.

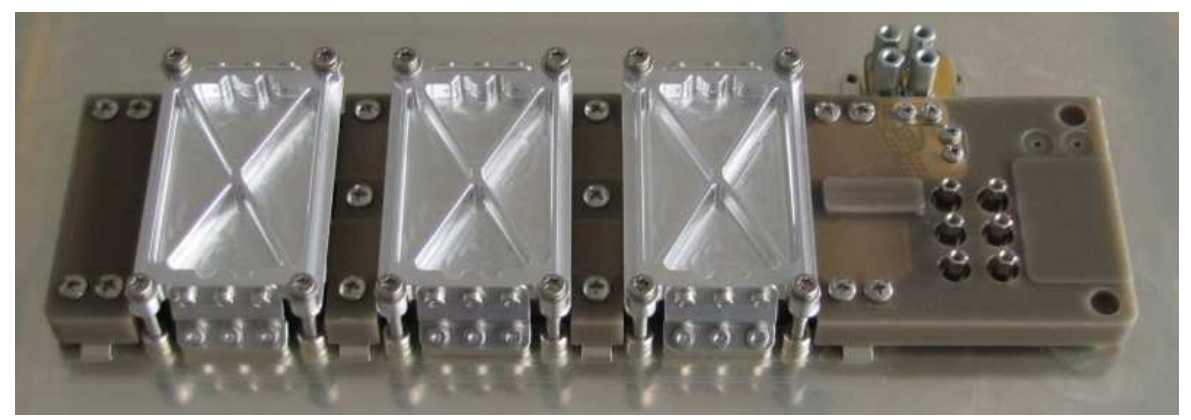

Figure 10: Planar Magnetic as part of the Flat Top Resonance Converter, 2kV, 2500W

\section{PERFORMANCE AND LIMITATIONS OF THE TECHNOLOGY}

Planar magnetics have many advantages for future designs. The most dominant is the simple manufacturing process of magnetics due to integration of the windings in a multilayer PCB. They are capable to resist high vibration loads if the mechanical construction is mature. Prototype manufacturing takes longer compared to wire wound magnetics because a complex multi-layer PCB needs to be designed and manufactured. Due to this there is a demand of improved prediction methods to get the development more and more into the direction of succeeding in the first run. The parameters of interest are a more precise determination of the power dissipation of magnetics, a prediction of the leakage inductance and the capacitive coupling between the layers of the
PCB. A well selected PCB stack and improved cooling concepts are an important part of the development. This knowledge helps to reduce the development time.

\subsection{PCB and Forced Cooling of magnetics}

The ECSS-Q-ST-70-12C limits the copper thickness within a multilayer PCBs to $70 \mathrm{um}$. This is necessary to fulfil the high reliability requirements on PCBs used for space applications. Improved future technologies are necessary to gain in higher power density.

The E-Planar-Cores occupy more PCB area compared to wire wound magnetics and gain from a low component height. The heat dissipation can be spread over a large area of the PCB reducing operational temperatures. There plain geometry opens new effective ways 
of forced cooling as depicted in Figure 10. The cores are surrounded by aluminium elements transferring the power dissipation directly to the structure. Compared to Toroid or Pot cores a very low thermal resistance can be reached to cool the PCB and the ferrite core as well. This advantage makes that core geometry well suited for high power applications. The preferred properties of PCBs are a high thermal conductivity and low $\varepsilon r$.

\subsection{Power Dissipation of Magnetics}

PCBs for power converters are complex due to the coexistence of high power and small signal components on the same PCB. Additionally the parts generate heat which has to be transferred to the mounting plate to keep the operational temperature within an acceptable range. A good calculation of losses is important to reduce the iteration loops of a design. A planar magnetic generates power dissipation by the AC-flux density in the ferrite core. The windings are affected by $\mathrm{I}^{2} \mathrm{R}$ current losses. They can be generated by DC- or by ACcurrent. The latter one is affected by the proximity effect which generates additionally losses by current displacement. A combination of the two effects can occur as well depending on the application. Gaped cores generate heat in the winding arrangement due to leakage flux.

Loss calculations are possible by advanced mathematical formulas or by finite element analysis. The mathematical approach is complex but offers the advantage that the different losses can be isolated in $\mathrm{DC}-\mathrm{I}^{2} \mathrm{R}$ losses, $\mathrm{AC}-\mathrm{I}^{2} \mathrm{R}$ losses per winding layer and gap losses. An understanding of the loss generation by the different effects combined helps to do a first optimisation. The calculation by finite element method requires mostly a high data processing power which exceeds that one of a standard desktop computer. It provides a detailed view on the results. Modelling takes longer but is more accurate in the end.

\subsection{Prediction of leakage inductance and capacitive coupling}

Leakage inductance is a common parasitic component in multiple-winding magnetics. It is due to the stray magnetic flux leaking out of the core, between adjacent windings, thus not linked to all the windings. Coupling capacitance is mainly generated at the interface between turns (of the same winding or between different windings). It is effective in case of a non-zero relative voltage swing.

Leakage inductance generates losses in RC-Snubbers and RCD-Clamping networks while coupling capacitance reduces the resonance frequency of a magnetic. In most applications these components are undesired and shall therefore be minimized.

Planar technology is inherently prone to high coupling capacitance due to the flat copper tracks and the small distance between layers. On the other hand, the same characteristics typically tend to decrease the leakage inductance.

Table 5 outlines how low values of leakage inductance and parasitic capacitance are contrary properties of a magnetic. A typical optimization scenario consists in reducing the effective parasitic capacitance while keeping the leakage inductance under a given value. Approaches 3 and 4 , in particular, have the advantage of reducing the effective coupling capacitance without significantly affecting the leakage inductance, they should therefore be preferred.

Table 5: Common magnetic optimization techniques

\begin{tabular}{|c|c|c|c|}
\hline $\mathrm{N}$ & & $\mathrm{C}_{\text {eff }}$ & $\mathrm{L}_{\text {Leak }}$ \\
\hline 1 & Winding Interleaving & $\uparrow$ & $\downarrow$ \\
\hline 2 & $\begin{array}{c}\text { Reduced thickness of layer } \\
\text { stack by less insulation }\end{array}$ & $\uparrow$ & $\downarrow$ \\
\hline 3 & $\begin{array}{c}\text { Air (vacuum) spacers be- } \\
\text { tween windings }\end{array}$ & $\downarrow$ & - \\
\hline 4 & $\begin{array}{c}\text { Voltage swing matching with- } \\
\text { in the layer-stack }\end{array}$ & $\downarrow$ & - \\
\hline
\end{tabular}

The properties of planar magnetics are very reproducible compared to wire wound types. This guarantees stable performance parameters and simplifies the modelling. The Gyrator-Capacitor model in [2] offers good flexibility and accuracy to analyse and compare different possible designs solutions. Figure 11 shows an example of application of the Gyrator-Capacitor model where the windings coupled to the core are represented by gyrators while the magnetics core is modelled by a capacitor. The magnetization admittance $\left(1 / \mathcal{R}_{\text {core }}\right)$ becomes a capacitor connected in series with the magnetic side of all the gyrators. Similarly, leakage admittance paths between adjacent windings are modelled by capacitors connected in between windings which are represented by gyrators. Capacitive coupling within the layer stack is modelled by connecting capacitors between the centre of the windings on the electric side. Thus, a multiple of two Gyrators is necessary to represent each winding, in order to make the point of average voltage electrically accessible. 

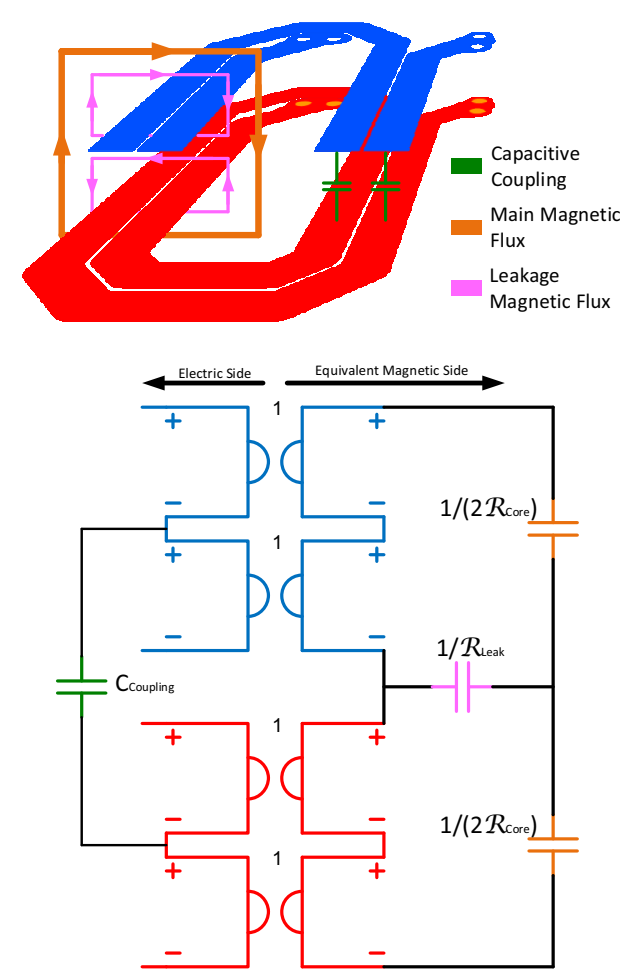

Figure 11: Example of Coupling Capacitance and Leakage Inductance with Gyrator-Capacitor Model as in [2]

The parasitic components (Coupling Capacitance and Leakage Reluctance) in the model can be estimated with the following formulas:

$\mathrm{C}_{\text {Coupling }} \approx \varepsilon_{0} \cdot \varepsilon_{\mathrm{r}} \cdot \mathrm{S}_{\text {Ovlp }} / \mathrm{d}, \varepsilon_{0}=8.85 \cdot 10^{-12} \mathrm{~F} / \mathrm{m}$

$\mathcal{R}_{\text {Leak }} \approx \mathrm{w} /\left(l_{\text {Avg }} \cdot \mu_{0}\right), \quad \mu_{0}=4 \pi \cdot 10^{-7} \mathrm{~N} / \mathrm{A}^{2}$

Where $\varepsilon_{0}$ is the electrical field constant, $\varepsilon_{\mathrm{r}}$ the permittivity of the dielectric, $S_{\text {Ovlp }}$ the total overlapping surface, $d$ the vertical distance between the windings, $w$ the winding width and $l_{\mathrm{Avg}}$ the average turn length.

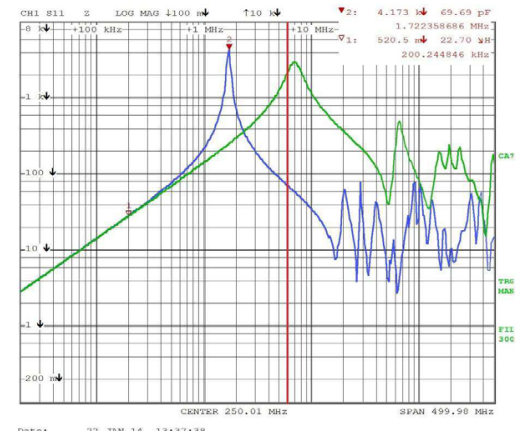

Figure 12: Impedance plot of a coupled magnetic without optimisation in blue colour and with optimisation in green.

\subsection{Planar magnetics with limited performance}

Planar chokes using Pot- and E-cores have usually a single airgap to provide energy storage capability. Applications with a high operational AC switching current generate high $\mathrm{AC}$ magnetic fields around the airgap and, as a consequence, generate high copper losses on adjacent PCB tracks. Applications for reference are the Phase Shift Converter with its resonance choke or a Flyback in discontinuous mode. Toroid cores with their distributed airgap are mostly the best choice for this kind of applications.

\section{REFERENCES}

1. Application Note of Philips Magnetic Products Planar E Core (7/1997)

2. David C. Hamill (1994). Gyrator-CapacitorModeling A Better Way of Understanding Magnetic Components, Department of Electronic and Electrical Engineering, University of Surry, Guildford GU2 5XH, Unoited Kingdom, IEEE 0-7803-1456-5/94

3. Strixner E., Godzik, S., Dr. Drechsler E. (2011). Optimization of an Integrated Planar Magnetic for active Antenna Panels. In Proc. of the 9th European Space Power Conference. Saint-Raphaël. France 